\title{
Vitamin D status in healthy Romanian caregivers and risk of respiratory infections
}

\author{
Alina C Porojnicu ${ }^{1, *}$, Ruxandra Moroti-Constantinescu², Andrei Laslau², \\ Zoya Lagunova ${ }^{1}$, Arne Dahlback ${ }^{3}$, Adriana Hristea ${ }^{2}$ and Johan Moan ${ }^{1,3}$ \\ 'Department of Radiation Biology, Institute for Cancer Research, Oslo University Hospital, Monetebllo 0301, \\ Oslo, Norway: ${ }^{2}$ Matei Bals National Institute for Infectious Diseases, Bucharest, Romania: ${ }^{3}$ Physics Institute, \\ University of Oslo, Oslo, Norway
}

Submitted 26 July 2011: Accepted 4 January 2012: First published online 14 March 2012

\begin{abstract}
Objectives: To investigate the vitamin D status during winter of a healthy population of hospital employees and to assess the correlation between vitamin D status and risk of infections in the upper respiratory tract.

Design: One hundred and ten healthy volunteers answered a questionnaire on their solar exposure habits and vitamin D intake and delivered one blood sample for quantification of vitamin D level (serum 25-hydroxyvitamin D (25(OH)D) concentration) during December 2007-January 2008. At the end of the winter we screened for the occurrence of respiratory infections and sought associations with vitamin D status.

Setting: Bucharest, Romania, $45^{\circ} \mathrm{N}$.

Subjects: One hundred and ten healthy hospital employees.

Results: Eighty per cent of participants were vitamin D deficient (25(OH)D level below $50 \mathrm{nmol} / \mathrm{l})$. The main determinant of serum $25(\mathrm{OH}) \mathrm{D}$ was sun exposure during the summer previous to the study $(P=0.02$ in multivariate analysis). Intake of vitamin D, BMI and age played no significant role for the level of $25(\mathrm{OH}) \mathrm{D}$. Overall we found a non-significant negative correlation between $25(\mathrm{OH}) \mathrm{D}$ level and new cases of infection (Spearman correlation coefficient of $-0 \cdot 12, P=0 \cdot 2$ ). Conclusions: Vitamin D status is alarmingly poor in active, relatively young women residing in Romania. If our results are reproduced by other investigations, action to improve vitamin D status at the population level is necessary. We were not able to show a statistically significant relationship between vitamin D status and infection risk in our material.
\end{abstract}

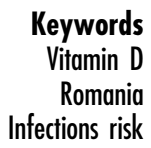

Keywords

Romania Infections risk
The important role of vitamin D in Ca metabolism and bone health is well accepted ${ }^{(1)}$. The discovery that most human tissues are able to produce and use active vitamin D triggered extensive research of vitamin D's biological functions beyond bone health. Experimental and epidemiological work has shown that vitamin $\mathrm{D}$ reduces risk and improves prognosis of cancer ${ }^{(2)}$. Moreover, vitamin D plays important roles in the regulation of innate and adaptive immunity and seems to decrease the risk and modulate the course of various infections ${ }^{(3-6)}$. Vitamin D itself has low biological activity, but undergoes activation by successive hydroxylations: in the liver with the formation of 25-hydroxyvitamin D (25(OH)D) and in the kidney with the production of 1,25-dihydroxyvitamin D $\left(1,25(\mathrm{OH})_{2} \mathrm{D}\right)^{(7)}$. It is becoming increasingly clear that $1,25(\mathrm{OH})_{2} \mathrm{D}$ also can be produced outside the kidney. This local production may have very important implications for the effects of vitamin D on health.
The body is able to synthesize vitamin D upon sufficient UV exposure. In fact, skin synthesis is the main source of vitamin D in most populations, proving a high efficiency of this reaction when the oral intake (from regular poor diet) is low ${ }^{(8)}$. It is believed that a whole-body exposure at one MED (minimal erythema dose) generates 250-500 $\mu \mathrm{g}$ (10 000-20000 IU) of vitamin D, which is equivalent to the vitamin D content of $250 \mathrm{ml}$ of cod-liver oil ${ }^{(9-11)}$.

Since man is to a high degree dependent on the skin production of vitamin $\mathrm{D}$, factors altering either the fluence rate of UV radiation (like altitude, latitude, cloud cover, clothing habits, use of sun screens) or skin properties (like skin colour, age) are the main predictors of vitamin D status.

Romania is located at a latitude of $45^{\circ} \mathrm{N}$ which ensures a sufficient UV fluence rate to efficiently produce vitamin D from March to October ${ }^{(12)}$. At the same time, Romanians have no practice of vitamin D food fortification or tradition of cod-liver oil consumption. This means that their 
biological pool of vitamin D has to accumulate during summer. We recruited for our study healthy medical employees (resident doctors and nurses) working in one of the main hospitals of Bucharest. Our aim was to investigate their vitamin D status and its association with risk of developing respiratory tract infections during the study period.

\section{Materials and methods}

\section{Participants}

One hundred and ten healthy volunteers were recruited from medical employees in a university hospital in Bucharest, Romania (Matei Bals National Institute for Infectious Diseases). Pregnant women were excluded from the study. The study took place between 1 December 2007 and 15 March 2008 and was approved by the Romanian Academy of Medical Science, the Matei Bals National Institute for Infectious Disease's Ethics Commission and Steering Committee. Each volunteer signed a consent form before entering the study.

\section{Food and sun questionnaire}

We used a six-page self-administered quantitative questionnaire which is a simplified version of the one used by Brustad et al. in the European Prospective Investigation into Cancer and Nutrition ${ }^{(13)}$. The questionnaire contained questions about intake of food items known to contain vitamin D (about twenty-five food items and dishes). The frequency of use was given per day, week or month and the portion size was given in slices, glasses or spoons. Vitamin D intake was calculated based on standard weights. We also asked questions on supplements after checking the market for specific compounds. We also assessed the solar exposure by asking questions on holiday length/location during the summer prior to the study, skin type (assessed on a colour scale according to Fitzpatrick $^{(14)}$ ) and use of sunscreen (with protection factor). Information on gender, age and BMI $\left(\mathrm{kg} / \mathrm{m}^{2}\right)$ was also collected.

\section{Sampling}

Blood samples were collected during December 2007January 2008. A $10 \mathrm{ml}$ peripheral venous blood sample was obtained from each volunteer and centrifuged for serum separation. Serum was collected, transferred into coded tubes and stored at $-80^{\circ} \mathrm{C}$. The samples were shipped on ice and analysed in one batch at the Hormone Laboratory, Aker University Hospital, Oslo, Norway.

\section{Identification of infections}

Volunteers were asked to continuously report to the main physician investigator (an infectious diseases specialist) any sign and symptom of respiratory infections. Respiratory tract infection episodes (sinusitis, tonsillitis, laryngotracheitis and pneumonia) were recorded along with any use of antibiotics. We also counted the number of conjunctivitis episodes since this is a common symptom in upper respiratory infections. Some of the upper respiratory tract infections and most of the lower respiratory tract infections were confirmed by objective analysis, as sinuses and pulmonary $\mathrm{X}$-ray respectively and biological samples.

\section{Biochemical analyses}

The concentration of $25(\mathrm{OH}) \mathrm{D}$ was determined by HPLC after diethyl ether extraction essentially as described by Falch et $a l .{ }^{(15)}$, with an inter-assay variation of $12 \%$.

\section{Statistical analyses}

The level of numerical variables (age, BMI, vitamin D intake, serum $25(\mathrm{OH}) \mathrm{D}$ concentration, number of infectious events) was expressed as the mean and standard deviation. The contribution of each variable in explaining the measured level of $25(\mathrm{OH})$ D was determined using multiple regression analysis and results are given as $R^{2}$ with $P$ values. The association between $25(\mathrm{OH}) \mathrm{D}$ level and incidence of respiratory tract diseases was explored using a Spearman correlation test. Serum levels of $25(\mathrm{OH}) \mathrm{D}$ were categorized as $<30 \mathrm{nmol} / 1,30-49 \mathrm{nmol} / 1$, $50-79 \mathrm{nmol} / 1$ and $>80 \mathrm{nmol} / 1$. The limit for statistical significance was set to be equal to $0 \cdot 05$. Statistical tests were performed with the SPSS for Windows statistical software package version 12 (SPSS Inc., Chicago, IL, USA).

\section{Results}

Out of the 110 volunteers who delivered a blood sample, 105 completed the questionnaire. Five individuals were excluded from the analysis due to lack of follow-up on infectious episodes. This left us with a group of 100 volunteers for the final analysis. The characteristics of the study population are described in Table 1.

The main result of the present work is that $97 \%$ of our volunteers had a serum level of $25(\mathrm{OH}) \mathrm{D}$ below $80 \mathrm{nmol} / \mathrm{l}$. Eighty per cent had a level below $50 \mathrm{nmol} / \mathrm{l}$ and $35 \%$ had 25(OH)D concentration below $30 \mathrm{nmol} / 1$ (Fig. 1). Men were under-represented in our study; therefore conclusions apply primarily to healthy women. We were able to include only five males and their mean 25(OH)D level was $29 \cdot 8$ (sD $5 \cdot 5$, range $23-36$ ) $\mathrm{nmol} / \mathrm{l}$.

We analysed, independently as well as in a multivariate model, the predictor role of vitamin D intake, sun exposure, BMI, age and skin type on vitamin D status. Out of all these parameters assessed from the questionnaire, only sun exposure during the previous summer was significantly correlated with the level of $25(\mathrm{OH}) \mathrm{D}(P=0 \cdot 001$; Table 2$)$. We observed that a 2 -week holiday predicted a winter $25(\mathrm{OH}) \mathrm{D}$ level of about $50 \mathrm{nmol} / \mathrm{l}$, while no holiday resulted in a level of about $30 \mathrm{nmol} / 1$. As expected, there 
Table 1 Descriptive characteristics of the participating population: healthy Romanian volunteers ( $n$ 105), December 2007-January 2008

\begin{tabular}{lc}
\hline Characteristic & Value \\
\hline Total number & 105 \\
Gender $(n)$ & 105 \\
Females (\%) & $94 \cdot 3$ \\
Males (\%) & $5 \cdot 7$ \\
Age (years) & \\
Mean & $35 \cdot 3$ \\
SD & $8 \cdot 2$ \\
Range & $20-57$ \\
BMI (kg/m $\left.{ }^{2}\right)$ & \\
Mean & $24 \cdot 0$ \\
SD & $5 \cdot 1$ \\
Range & $14 \cdot 7-39 \cdot 1$ \\
Vitamin D intake ( $\mu \mathrm{g} / \mathrm{d})$ & \\
Mean & $5 \cdot 9$ \\
SD & $5 \cdot 4$ \\
Range & $0-40$ \\
Skin type $(n)$ & 90 \\
1 (\%) & $13 \cdot 3$ \\
$2(\%)$ & $52 \cdot 2$ \\
$3(\%)$ & $34 \cdot 5$ \\
Sun exposure $(n)$ & 91 \\
$<1$ week (\%) & $40 \cdot 6$ \\
$1-2$ weeks $(\%)$ & $36 \cdot 2$ \\
$>2$ weeks (\%) & $23 \cdot 1$ \\
Sunscreen use $(n)$ & 91 \\
No use & $27 \cdot 5$ \\
SPF $<15(\%)$ & $27 \cdot 5$ \\
SPF $>15(\%)$ & $45 \cdot 0$ \\
\hline
\end{tabular}

SPF, sun protection factor.

Blood samples were collected in December 2007-January 2008.

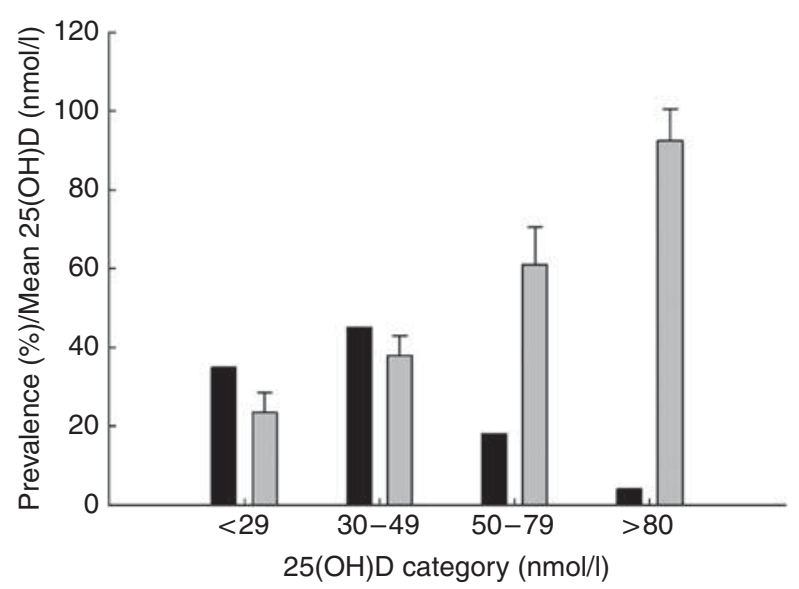

Fig. 1 Prevalence of low 25-hydroxyvitamin D (25(OH)D) concentration $(\square)$ and mean 25(OH)D concentration ( $\square$; standard deviation represented by vertical bars) according to $25(\mathrm{OH}) \mathrm{D}$ category among healthy Romanian volunteers ( $n$ 105), December 2007-January 2008.

seemed to be a positive correlation between serum $25(\mathrm{OH}) \mathrm{D}$ concentration and vitamin $\mathrm{D}$ intake and a negative one with $\mathrm{BMI}$, but these associations did not reach statistical significance $(P=0 \cdot 3$ and $0 \cdot 3$, respectively). Volunteers had skin type 1,2 or 3 with most of them belonging to type 2 (Table 1 ) but we found no correlation between skin type and vitamin D status in our study (data not shown).
Table 2 Results of linear regression analysis of the relationship between age, BMI, vitamin D intake and sun exposure during the summer previous to the study and serum $25(\mathrm{OH}) \mathrm{D}$ level: healthy Romanian volunteers ( $n$ 105), December 2007-January 2008

\begin{tabular}{lccc}
\hline $\begin{array}{l}\text { Predictor of serum } \\
\text { 25(OH)D level }\end{array}$ & $\begin{array}{c}\text { Regression } \\
\text { coefficient }\end{array}$ & SE & $\begin{array}{c}R^{2} \text { of the } \\
\text { multivariate model }\end{array}$ \\
\hline Age (years) & 0.47 & 0.65 & 0.1 \\
BMl $\left(\mathrm{kg} / \mathrm{m}^{2}\right)$ & -0.89 & 0.38 & \\
Intake $(\mu \mathrm{g} / \mathrm{d})$ & 0.73 & 0.47 & \\
Weeks of holiday & 3.33 & 0.001 & \\
\hline
\end{tabular}

25(OH)D, 25-hydroxyvitamin D.

Another aim of our study was to assess the frequency of upper and lower respiratory tract infectious episodes and to look for a correlation between these and serum $25(\mathrm{OH}) \mathrm{D}$ level. Twenty-one per cent of our volunteers experienced one or more episodes of sinusitis. The incidence for tonsillitis was $37 \%, 8 \%$ for conjunctivitis, $28 \%$ for laryngotracheitis and $2 \%$ for pneumonia. Twenty per cent of the population experienced one or more fever episodes and $30 \%$ of them were subjected to one or more antibiotic sessions during the study period. Overall, $32 \cdot 4 \%$ of volunteers did not experience any infection episode while $29 \cdot 4 \%$ experienced one episode and $37 \cdot 2 \%$ had two or more infection episodes. Table 3 presents the occurrence of none, one and two or more episodes with their corresponding $25(\mathrm{OH}) \mathrm{D}$ levels. Due to the low number of some of the clinical outcomes, we chose to look at the correlation between $25(\mathrm{OH})$ level and the occurrence of any upper respiratory tract infection, unstratified by localization. Overall we found no statistical significant correlation between serum level of $25(\mathrm{OH}) \mathrm{D}$ and occurrence of infections in our material, with a Spearman correlation coefficient of $-0 \cdot 12, P=0 \cdot 2$.

\section{Discussion}

The main aim of the present study was to map the vitamin D status in a seemingly healthy Romanian population and to seek correlations between this and vitamin D intake, sun exposure during the summer previous to the study, age, BMI and risk for respiratory infections during the winter period. Romania is located at $45^{\circ} \mathrm{N}$ and has warm summers. Romanians residing in the capital (the place of the study) have generally no tradition for eating fish or supplementing with cod-liver oil, and food fortification is an inconsistent and almost non-existent practice. Therefore, most Romanians are dependent on cutaneous production of vitamin D to fill their physiological needs.

We report here alarmingly low $25(\mathrm{OH}) \mathrm{D}$ levels, with $97 \%$ of our volunteers having concentrations below $80 \mathrm{nmol} / 1$ and almost one-third below $30 \mathrm{nmol} / 1$ (Fig. 1).

The understanding that vitamin D may play an important role in the prevention and cure of several chronic diseases has generated some controversy regarding the optimal level 
Table 3 Mean concentration of serum $25(\mathrm{OH}) \mathrm{D}(\mathrm{nmol} / \mathrm{l})$ stratified by disease status (number of episodes of upper respiratory tract infection): healthy Romanian volunteers ( $n$ 105), December 2007-January 2008

\begin{tabular}{|c|c|c|c|c|c|c|c|c|c|}
\hline \multirow[t]{2}{*}{ Number of episodes } & \multicolumn{3}{|c|}{0} & \multicolumn{3}{|c|}{1} & \multicolumn{3}{|c|}{2} \\
\hline & $n$ & Mean & SD & $n$ & Mean & SD & $n$ & Mean & SD \\
\hline Sinusitis ( $n$ 102) & 80 & $39 \cdot 5$ & $17 \cdot 8$ & 15 & $41 \cdot 3$ & $20 \cdot 8$ & 2 & $43 \cdot 0$ & $9 \cdot 9$ \\
\hline Tonsillitis (n 102) & 64 & $41 \cdot 5$ & $18 \cdot 5$ & 30 & $37 \cdot 5$ & $17 \cdot 2$ & 7 & $27 \cdot 5$ & $6 \cdot 7$ \\
\hline Laryngotracheitis ( $n$ 102) & 72 & $39 \cdot 2$ & $17 \cdot 3$ & 23 & $38 \cdot 5$ & $18 \cdot 0$ & 3 & $37 \cdot 3$ & $15 \cdot 3$ \\
\hline Conjunctivitis ( $n$ 102) & 93 & $38 \cdot 6$ & $17 \cdot 5$ & 8 & $39 \cdot 7$ & $15 \cdot 3$ & 0 & - & - \\
\hline Any infection ( $n$ 102) & 33 & $43 \cdot 5$ & $20 \cdot 0$ & 30 & $37 \cdot 0$ & $13 \cdot 0$ & 23 & $34 \cdot 0$ & $14 \cdot 7$ \\
\hline
\end{tabular}

25(OH)D, 25-hydroxyvitamin D; $n$, total number of cases; Mean and SD, mean serum 25(OH)D concentration (nmol/l) and standard deviation.

The Spearman coefficient for the correlation between $25(\mathrm{OH}) \mathrm{D}$ level and number of infectious episodes was $0 \cdot 12, P=0 \cdot 02$.

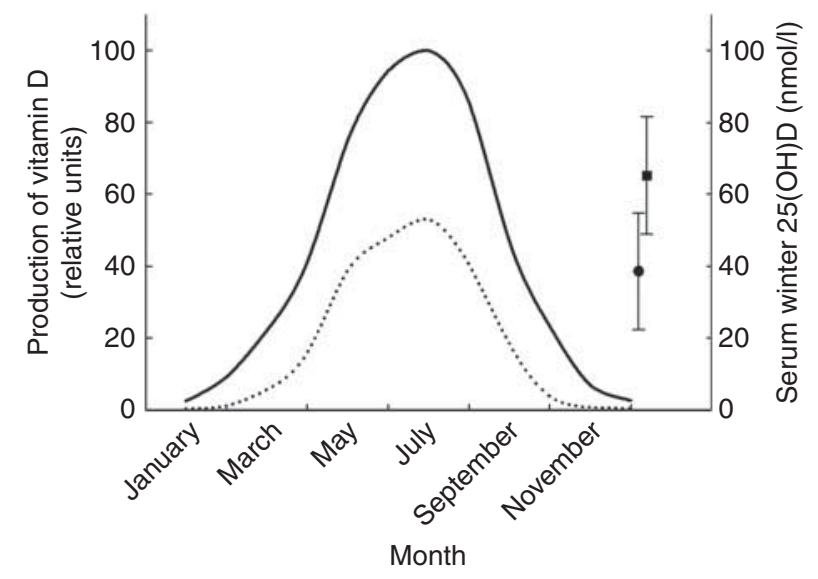

Fig. 2 Seasonal variation in the UV fluence rate in Bucharest $\left(45^{\circ} \mathrm{N} ;-\right)$ and Oslo $\left(60^{\circ} \mathrm{N} ; \cdots\right)$ and the average concentration of 25-hydroxyvitamin $\mathrm{D}(25(\mathrm{OH}) \mathrm{D})$ during the winter ( $\bullet$, Bucharest; $\mathbf{\square}$, Oslo; standard deviation represented by vertical bars) in two similar healthy populations.

of vitamin D. Recently a panel of experts agreed that the $25(\mathrm{OH}) \mathrm{D}$ level should be above $75 \mathrm{nmol} / \mathrm{l}$ for optimal health benefit ${ }^{(16)}$, and it is known that a level of $30 \mathrm{nmol} / 1$ is the threshold for avoiding rickets in infants and osteomalacia in adults ${ }^{(17)}$. Our results are surprising, since our population consisted of young, active and healthy medical caregivers who supposedly have higher health awareness than the average population. Among all parameters investigated, only sun exposure during the previous summer was a significant predictor of serum 25(OH)D level (Table 2). This is in agreement with several other publications showing a significant correlation between summer levels and winter levels, pointing once more to the importance of cutaneous vitamin D synthesis in predicting serum 25(OH)D levels ${ }^{(18-20)}$. On the other hand, our results seem to indicate that $25(\mathrm{OH}) \mathrm{D}$ has a longer half-life than previously reported $^{(21)}$ but we cannot attempt any calculation since we have not measured summer concentrations of $25(\mathrm{OH}) \mathrm{D}$. Figure 2 presents the seasonal variation of the UV fluence rate in Bucharest $\left(45^{\circ} \mathrm{N}\right)$ and Oslo $\left(60^{\circ} \mathrm{N}\right)$ and the average $25(\mathrm{OH}) \mathrm{D}$ concentration during the winter in two similar healthy populations. It is surprising that despite higher fluence during the summer in Bucharest, the residual 25(OH)D level during winter is significantly lower in Bucharest than in Oslo $(38.5 \mathrm{nmol} / 1$ v. $65 \cdot 2 \mathrm{nmol} / \mathrm{l})$. This seems to indicate that other factors like the tradition of fish consumption and sun-seeking behaviour (common among Norwegians) play important roles in determining vitamin D status ${ }^{(22)}$.

Ageing is a known factor that modifies vitamin D production $^{(23)}$. We found no correlation between age and vitamin D status, but this may be due to the narrow age span of our population and its relatively low mean age ( 35.5 years). The same is true for BMI. It has been reported by several scientists that high BMI is associated with low vitamin D status (due to trapping of vitamin D in excess body fat and reduced solar exposure, especially in extremely obese patients) ${ }^{(24-26)}$. Our volunteers had BMI in the range from 14.7 to $39 \cdot 1 \mathrm{~kg} / \mathrm{m}^{2}$, and we observed a slight but non-significant negative correlation with serum 25(OH)D (Table 2).

The mean vitamin $\mathrm{D}$ intake in our population was $5.9 \mu \mathrm{g} / \mathrm{d}$. We have previously shown that intake in this range is too low to maintain a summer level of $25(\mathrm{OH}) \mathrm{D}^{(27)}$. Our present data show, as expected, a positive but nonsignificant correlation between vitamin $\mathrm{D}$ intake and serum $25(\mathrm{OH}) \mathrm{D}$ concentration (Table 2$)$. In a recent metaregression analysis of the vitamin D intake-serum 25(OH)D relationship, an intake of $5 \mu \mathrm{g} / \mathrm{d}$ during winter would predict serum levels of about $35 \mathrm{nmol} / 1$, which is in good agreement with our present data ${ }^{(28)}$.

Our results seem to indicate that despite high UV fluence during the summer, Romanians' vitamin D status during winter is far below optimal. This shows that sun exposure of just the hands/face (walking to and from work, normal outdoor daily activities in the city) is not sufficient to generate satisfactory levels of vitamin $\mathrm{D}$, not even in Romania. This may be related to the fact that Romanians probably seek shade during the summer (due to high temperatures, notably in cities with intense traffic and large concrete buildings). We observed that volunteers who had a 2-week holiday at the seaside the summer previous to the study had significantly higher levels of $25(\mathrm{OH}) \mathrm{D}$ during the winter than the other volunteers. Vitamin D intake reported by our volunteers in the questionnaire had little impact on the $25(\mathrm{OH}) \mathrm{D}$ serum level (although we observed a positive but non-significant correlation). 
We further recorded the occurrence of respiratory symptoms and the use of antibiotics during the period of the study. Our hypothesis was that a low vitamin D status will increase the risk of infections. The respiratory tract serves as the primary interface between the host and inhaled pathogens. Mucosa is equipped with various defence mechanisms such as: (i) the ciliary beat, cough reflex and mucus clearance; (ii) the secretion of antimicrobial peptides (like defensins and cathelicidin); and (iii) initiation of the inflammatory response and recruitment of phagocytic cells. Vitamin D regulates the production of cathelicidin and defensins ${ }^{(29,30)}$. These are molecules produced in the epithelium of the upper and lower respiratory tracts that have antimicrobial activity, increase pro-inflammatory gene expression, are involved in reparatory mechanisms of the epithelium and induce maturation of dendritic cells.

Several clinical reports suggest that poor vitamin D status is a factor predisposing to infections of the upper and lower respiratory tracts. In Finland soldiers with low vitamin D status ( $<40 \mathrm{nmol} / \mathrm{l})$ at entry into military service have a higher risk for subsequent respiratory infections $^{(31)}$. Similar results are reported also in Turkey ${ }^{(32)}$ and India ${ }^{(33)}$, where levels below $50 \mathrm{nmol} / 1$ significantly increased the risk of respiratory infections in children and neonates. A recent American study reports 55\% higher odds of developing respiratory infections if $25(\mathrm{OH}) \mathrm{D}$ concentration is below $25 \mathrm{nmol} / 1$ compared with above $75 \mathrm{nmol} / \mathrm{l}^{(34)}$. Our results showed no significant overall trend of covariance of infection occurrence and vitamin D levels. Our negative results may be due to the fact that only $4 \%$ of the volunteers had a $25(\mathrm{OH}) \mathrm{D}$ level above $80 \mathrm{nmol} / \mathrm{l}$ and because of the relatively short duration of our study. Interpretation of the results is also weakened by the fact that disease occurrence was self-reported in some cases, without paraclinical confirmation.

To our knowledge the present study the first one that has evaluated the vitamin D status in a relatively young, active population in Romania. We acknowledge that the study has limitations: relatively low number of participants and high homogeneity (mostly females, low ranges of age, vitamin D intake, BMI) that make the analysis of associations difficult. Nevertheless, we report alarmingly low levels of $25(\mathrm{OH}) \mathrm{D}$ that should trigger more studies in larger population groups. We advocate here for information campaigns on the importance of vitamin $\mathrm{D}$ for health, consistent enrichment of food and encouragement of assessing vitamin D levels, at least in sick people and populations at risk.

\section{Acknowledgements}

This paper was partially supported by the Sectoral Operational Programme Human Resources Development (SOP HRD), financed from the European Social Fund and by the Romanian Government under contract number POSDRU/89/1.5/S/64109. The financial support of the Norwegian Cancer Association is highly appreciated. The Norwegian authors received support from the Norwegian Cancer Society and Health South-East Medical Enterprise. There are no conflicts of interest. The authors' contributions were as follows: R.M.-C., A.L. and A.H., collection of data, interview with the patients, blood sampling; A.C.P., Z.L. and J.M., measurement of serum 25(OH)D levels, data analyses; A.D., analyses of spectral data.

\section{References}

1. Bischoff-Ferrari HA, Willett WC, Wong JB et al. (2005) Fracture prevention with vitamin D supplementation: a meta-analysis of randomized controlled trials. JAMA 293, $2257-2264$.

2. Holick MF (2010) Vitamin D: extraskeletal health. Endocrinol Metab Clin North Am 39, 381-400.

3. Chesney RW, Rosen JF, Hamstra AJ et al. (1981) Absence of seasonal variation in serum concentrations of 1,25 dihydroxyvitamin D despite a rise in 25-hydroxyvitamin D in summer. J Clin Endocrinol Metab 53, 139-142.

4. Hewison M (2010) Vitamin D and the immune system: new perspectives on an old theme. Endocrinol Metab Clin North Am 39, 365-379.

5. Miller J \& Gallo RL (2010) Vitamin D and innate immunity. Dermatol Ther 23, 13-22.

6. White JH (2010) Vitamin D as an inducer of cathelicidin antimicrobial peptide expression: past, present and future. J Steroid Biochem Mol Biol 121, 234-238.

7. Holick MF (1994) Vitamin D: photobiology, metabolism and clinical application. In The Liver: Biology and Photobiology, pp. 543-562 [IM Arias, JL Boyer, N Fausto et al., editors]. New York: Raven Press.

8. Helsedirektoratet og Universitetet i Oslo (2006) Søk i Matvaretabellen 2006 (MVT-06). http://matportalen.no/ matvaretabellen/index_html/main_view_eng (accessed January 2012).

9. Davie MW, Lawson DE, Emberson C et al. (1982) Vitamin D from skin: contribution to vitamin D status compared with oral vitamin $\mathrm{D}$ in normal and anticonvulsant-treated subjects. Clin Sci (Lond) 63, 461-472.

10. Holick MF (1995) Environmental factors that influence the cutaneous production of vitamin D. Am J Clin Nutr 61, 3 Suppl., 638S-645S.

11. Stamp TC, Haddad JG \& Twigg CA (1977) Comparison of oral 25-hydroxycholecalciferol, vitamin $\mathrm{D}$, and ultraviolet light as determinants of circulating 25-hydroxyvitamin D. Lancet 1, 1341-1343.

12. Webb AR, Kline L \& Holick MF (1988) Influence of season and latitude on the cutaneous synthesis of vitamin $\mathrm{D}_{3}$ : exposure to winter sunlight in Boston and Edmonton will not promote vitamin $\mathrm{D}_{3}$ synthesis in human skin. J Clin Endocrinol Metab 67, 373-378.

13. Brustad M, Braaten $\mathrm{T}$ \& Lund E (2004) Predictors for cod-liver oil supplement use - the Norwegian Women and Cancer Study. Eur J Clin Nutr 58, 128-136.

14. Fitzpatrick TB (1988) The validity and practicality of sun-reactive skin types I through VI. Arch Dermatol 124, 869-871.

15. Falch JA, Oftebro H \& Haug E (1987) Early postmenopausal bone loss is not associated with a decrease in circulating levels of 25-hydroxyvitamin D, 1,25-dihydroxyvitamin D, or vitamin D-binding protein. J Clin Endocrinol Metab 64, 836-841. 
16. Souberbielle JC, Body JJ, Lappe JM et al. (2010) Vitamin D and musculoskeletal health, cardiovascular disease, autoimmunity and cancer: recommendations for clinical practice. Autoimmun Rev 9, 709-715.

17. Zittermann A (2006) Vitamin D and disease prevention with special reference to cardiovascular disease. Prog Biophys Mol Biol 92, 39-48.

18. Burgaz A, Akesson A, Michaelsson K et al. (2009) 25-Hydroxyvitamin D accumulation during summer in elderly women at latitude 60 degrees N. J Intern Med 266, 476-483.

19. Thieden E, Philipsen PA, Heydenreich J et al. (2009) Vitamin D level in summer and winter related to measured UVR exposure and behavior. Photochem Photobiol 85, 1480-1484.

20. Webb AR, Kift R, Durkin MT et al. (2010) The role of sunlight exposure in determining the vitamin $\mathrm{D}$ status of the UK white adult population. Br J Dermatol 163, 1050-1055.

21. Clements MR, Davies M, Hayes ME et al. (1992) The role of 1,25-dihydroxyvitamin $\mathrm{D}$ in the mechanism of acquired vitamin D deficiency. Clin Endocrinol (Oxf) 37, 17-27.

22. Moan J, Porojnicu AC, Robsahm TE et al. (2005) Solar radiation, vitamin $\mathrm{D}$ and survival rate of colon cancer in Norway. J Photochem Photobiol B 78, 189-193.

23. Holick MF, Matsuoka LY \& Wortsman J (1989) Age, vitamin D, and solar ultraviolet. Lancet 2, 1104-1105.

24. Lagunova Z, Porojnicu AC, Lindberg F et al. (2009) The dependency of vitamin $\mathrm{D}$ status on body mass index, gender, age and season. Anticancer Res 29, 3713-3720.

25. Lagunova Z, Porojnicu AC, Grant WB et al. (2010) Obesity and increased risk of cancer: does decrease of serum 25-hydroxyvitamin D level with increasing body mass index explain some of the association? Mol Nutr Food Res 54, $1127-1133$.
26. Wortsman J, Matsuoka LY, Chen TC et al. (2000) Decreased bioavailability of vitamin D in obesity. Am J Clin Nutr 72, 690-693.

27. Porojnicu AC, Bruland OS, Aksnes L et al. (2008) Sun beds and cod liver oil as vitamin D sources. $J$ Photochem Photobiol B 29, 125-131.

28. Cashman KD, Fitzgerald AP, Kiely M et al. (2011) A systematic review and meta-regression analysis of the vitamin $\mathrm{D}$ intake-serum 25-hydroxyvitamin D relationship to inform European recommendations. Br J Nutr 106, 1638-1648.

29. Adams JS \& Hewison M (2008) Unexpected actions of vitamin D: new perspectives on the regulation of innate and adaptive immunity. Nat Clin Pract Endocrinol Metab 4, 80-90.

30. Gombart AF, Borregaard N \& Koeffler HP (2005) Human cathelicidin antimicrobial peptide (CAMP) gene is a direct target of the vitamin $\mathrm{D}$ receptor and is strongly upregulated in myeloid cells by 1,25-dihydroxyvitamin $\mathrm{D}_{3}$. FASEB J 19, 1067-1077.

31. Laaksi I, Ruohola JP, Tuohimaa P et al. (2007) An association of serum vitamin D concentrations $<40 \mathrm{nmol} / 1$ with acute respiratory tract infection in young Finnish men. Am J Clin Nutr 86, 714-717.

32. Karatekin G, Kaya A, Salihoglu O et al. (2009) Association of subclinical vitamin D deficiency in newborns with acute lower respiratory infection and their mothers. Eur J Clin Nutr 63, 473-477.

33. Wayse V, Yousafzai A, Mogale K et al. (2004) Association of subclinical vitamin D deficiency with severe acute lower respiratory infection in Indian children under 5 y. Eur J Clin Nutr 58, 563-567.

34. Ginde AA, Mansbach JM \& Camargo CA (2009) Association between serum 25-hydroxyvitamin $\mathrm{D}$ level and upper respiratory tract infection in the Third National Health and Nutrition Examination Survey. Arch Intern Med 169, 384-390. 